\title{
SHV-7, a Novel Cefotaxime-Hydrolyzing $\beta$-Lactamase, Identified in Escherichia coli Isolates from Hospitalized Nursing Home Patients
}

\author{
PATRICIA A. BRADFORD, ${ }^{1 *}$ CARL URBAN,${ }^{2,3}$ ARUN JAISWAL ${ }^{2}$ NORIEL MARIANO, ${ }^{2}$ \\ BETH A. RASMUSSEN, ${ }^{1}$ STEVEN J. PROJAN, ${ }^{1}$ JAMES J. RAHAL, ${ }^{2,4}$ \\ AND KAREN BUSH ${ }^{1}$ \\ Lederle Laboratories, Pearl River, New York ${ }^{1}$; The New York Hospital Medical Center of Queens, \\ Flushing, New York ${ }^{2}$; and Departments of Medicine $e^{4}$ and Microbiology, ${ }^{3}$ \\ Cornell University Medical College, New York, New York
}

Received 6 December 1994/Returned for modification 6 January 1995/Accepted 1 February 1995

\begin{abstract}
Four ceftazidime-resistant Escherichia coli strains were isolated from elderly nursing home patients in a New York hospital during 1993. Strains MCQ-2, MCQ-3, and MCQ-4 were determined to be identical by pulsedfield gel electrophoresis and plasmid profiles, whereas strain MCQ-1 was unique. Strain MCQ-1 was determined to produce a TEM-10 $\beta$-lactamase. Strains MCQ-2, MCQ-3, and MCQ-4 were also noted to be resistant to cefotaxime. These three strains produced two $\beta$-lactamases with pIs of 5.4 (TEM-1) and 7.6. $\beta$-Lactamase assays revealed that the pI 7.6 enzyme hydrolyzed cefotaxime faster (at a relative hydrolysis rate of $30 \%$ compared with that of benzylpenicillin) than either ceftazidime or aztreonam (relative hydrolysis rates of 13 and 3.3\%, respectively). Nucleotide sequencing of the gene encoding the pI 7.6 $\beta$-lactamase from strain MCQ-3 revealed a $b l a_{\mathrm{SHV}^{-}}$-type gene differing from the gene encoding $\mathrm{SHV}-1$ at four nucleotides which resulted in amino acid substitutions: phenylalanine for isoleucine at position 8 , serine for arginine at position 43 , serine for glycine at position 238 , and lysine for glutamate at position 240 . This novel SHV-type extended-spectrum $\beta$-lactamase is designated SHV-7.
\end{abstract}

Among gram-negative pathogens in the United States, the incidence of resistance to expanded-spectrum $\beta$-lactam antibiotics is becoming an ever-increasing problem. Outbreaks of ceftazidime-resistant Klebsiella pneumoniae and Escherichia coli have been reported recently in hospitals in Boston, Chicago, California, and New York $(7,18,21,29,34)$. In the Chicago outbreak, ceftazidime-resistant strains were associated with elderly nursing home patients $(27,35)$. In each outbreak, the occurrence of ceftazidime-resistant organisms was correlated with the increased use of ceftazidime in the hospitals.

The New York Hospital and Medical Center of Queens (NYHMCQ) in Flushing, N.Y., was one of the centers in which an outbreak of ceftazidime-resistant, cefotaxime-susceptible $K$. pneumoniae occurred $(18,34)$. In a 19-month period during 1988 to 1990 more than 400 strains of K. pneumoniae which expressed the TEM-26 $\beta$-lactamase were isolated. During the past several years, a continuous low level of ceftazidime-resistant $K$. pneumoniae isolates have been noted at NYHMCQ. In 1993 four strains of ceftazidime- and cefotaxime-resistant $E$. coli were isolated and selected for study. In three of these strains we have described and characterized a novel extendedspectrum $\beta$-lactamase, SHV-7, which confers resistance to cefotaxime as well as to ceftazidime and aztreonam.

\section{MATERIALS AND METHODS}

Bacterial strains. The bacterial strains and plasmids used in the study are listed in Table 1. E. coli MCQ-1, MCQ-2, MCQ-3, and MCQ-4 were ceftazidimeresistant clinical isolates from NYHMCQ. E. coli CAG12027 and DH5 $\alpha$ were used as recipients in mating and transformation experiments. Strains expressing

* Corresponding author. Phone: (914) 732-4396. Fax: (914) 7325687. Electronic mail address: Patricia_Bradford@internetmail.pr.cyanamid.com. the TEM-1, SHV-1, SHV-2, and SHV-4 $\beta$-lactamases were used as reference strains for $\beta$-lactamase studies.

Identification and susceptibility tests. Initial identification and susceptibility testing of the clinical isolates were performed by traditional manual biochemical tests and Bauer-Kirby disk diffusion tests in the clinical laboratory. The MICs and MBCs of various $\beta$-lactam antibiotics were determined by broth macrodilution tests by standard methods (19). The following antibiotics were obtained from the indicated sources: piperacillin (Lederle Laboratories, Pearl River, N.Y.); tazobactam (Taiho Laboratories, Tokushima, Japan); ticarcillin and potassium clavulanate (Beecham Laboratories, Bristol, Tenn.); ceftazidime (Glaxo Group Research Ltd., Greenford, England); cefotaxime (Hoechst-Roussel Pharmaceuticals Inc., Somerville, N.J.); imipenem (Merck, Rahway, N.J.); aztreonam and benzylpenicillin (Bristol-Myers Squibb, Princeton, N.J.); cephaloridine (Eli Lilly, Indianapolis, Ind.); cefotetan (Zeneca Pharmaceuticals, Wilmington, Del.); and cefoxitin (Sigma Chemical Company, St. Louis, Mo.). The conditions used for testing the $\beta$-lactam- $\beta$-lactamase inhibitor combinations were as follows: ampicillin-sulbactam, 2-to-1 ratio of drug to inhibitor; ticarcillin-clavulanate, constant concentration of $2 \mu \mathrm{g}$ of inhibitor per $\mathrm{ml}$; piperacillin-tazobactam, constant concentration of $4 \mu \mathrm{g}$ of inhibitor per $\mathrm{ml}$ and also a fixed 8-to-1 ratio of piperacillin to tazobactam. Markers of resistance of the transconjugants to non$\beta$-lactam antibiotics were determined by disk diffusion tests $(20)$.

IEF and $\beta$-lactamase assays. Crude preparations of $\beta$-lactamases from clinical isolates were obtained from sonic extracts prepared in $0.05 \mathrm{M}$ phosphate buffer (pH 7.0) (9). Isoelectric focusing (IEF) was performed by the method of Matthew et al. (16) with an LKB Multiphor apparatus with prepared PAGplates, $(\mathrm{pH}$ 3.5 to 9.5; Pharmacia LKB, Piscataway, N.J.). The $\mathrm{pH}$ gradient of the IEF gel was measured with a surface $\mathrm{pH}$ electrode. The $\mathrm{pI}$ of each enzyme was confirmed by activity staining with nitrocefin (Becton Dickinson Microbiology Systems, Cockeysville, Md.) following IEF.

For $\beta$-lactamase assays, all of the $\beta$-lactamases tested were initially purified by Sephadex G75 chromatography in $0.05 \mathrm{M}$ phosphate buffer ( $\mathrm{pH} 7.0)$ (33). The SHV-7 $\beta$-lactamase was further purified by ion-exchange chromatography on CM Sephadex C-50 (Pharmacia LKB) in $0.05 \mathrm{M}$ phosphate buffer (pH 7.4). The homogeneous enzyme had a $k_{\text {cat }}$ of $220 \mathrm{~s}^{-1}$ for cephaloridine. The activity of purified enzyme fractions was stabilized by returning the $\mathrm{pH}$ of the buffer to 7.0 with a final glycerol concentration of $10 \%$. Initial hydrolysis rates were monitored spectrophotometrically at $25^{\circ} \mathrm{C}$ in $0.05 \mathrm{M}$ phosphate buffer (pH 7.0) (26). The computer program ENZPACK (Biosoft, Cambridge, England) was used to calculate kinetic parameters by five methods of calculation (Direct Linear Plot, Lineweaver-Burk, Hanes-Woolf, Eadie-Hofstee, and the method of Wilkinson). Each substrate was analyzed on at least 2 days, with either cephaloridine or benzylpenicillin included as a reference on each day. Mean coefficients of variation were $26 \%$ for relative $V_{\max }$ values and $38 \%$ for $K_{m}$ values. Inhibition 
TABLE 1. Bacterial strains and plasmids used in the study

\begin{tabular}{|c|c|c|c|}
\hline Strain & Plasmid & Characteristics & Reference \\
\hline E. coli $\mathrm{MCQ}-1$ & & Clinical isolate & This study \\
\hline E. coli $\mathrm{MCQ}-2$ & & Clinical isolate & This study \\
\hline E. coli $\mathrm{MCQ}-3$ & & Clinical isolate & This study \\
\hline E. coli $\mathrm{MCQ}-4$ & & Clinical isolate & This study \\
\hline E. coli $\mathrm{MCQ}-1 \mathrm{X}$ & & Transconjugant of MCQ-1 expressing pI $5.6 \beta$-lactamase & This study \\
\hline E. coli MCQ-3Xa & & Transconjugant of MCQ-3 expressing pI $5.4 \beta$-lactamase & This study \\
\hline E. coli $\mathrm{MCQ}-3 \mathrm{Xb}$ & & Transconjugant of MCQ-3 expressing pI 5.4 and $7.6 \beta$-lactamases & This study \\
\hline E. coli $\mathrm{MCQ}-3 \mathrm{~T}$ & & Transformant of MCQ-3 expressing pI 5.4 and $7.6 \beta$-lactamases & This study \\
\hline E. coli $\mathrm{CAG} 12027$ & & MG1655 zdd-230::Tn9, $\beta$-lactam-susceptible, chlorampenicol-resistant recipient & 32 \\
\hline E. coli $\mathrm{DH} 5 \alpha$ & & E. coli $\mathrm{K}-12$ cloning strain & $\begin{array}{l}\text { Bethesda Research } \\
\text { Laboratories }\end{array}$ \\
\hline E. coli SC 10404 & & Identified in the Squibb Culture Collection as strain R6K expressing TEM-1 & 33 \\
\hline $\begin{array}{l}\text { K. pneumoniae } \\
\text { SC } 10999\end{array}$ & & Clinical isolate expressing SHV-1 and TEM-1 & 33 \\
\hline E. coli $\mathrm{W} 3110$ & pBP60 & Expressing SHV-2 $\beta$-lactamase & 14 \\
\hline E. coli $\mathrm{J} 53 \mathrm{Rif}^{\mathrm{r}}$ & pUD21 & Expressing SHV-4 $\beta$-lactamase & 8 \\
\hline E. coli $\mathrm{DH} 5 \alpha$ & pCLL2300 & Kanamycin-resistant cloning vector & 28 \\
\hline E. coli $\mathrm{DH} 5 \alpha$ & pCLL2306 & TEM-1 probe strain, $N d e \mathrm{I}-E c o$ RI fragment from PCR products of pUC19 & This study \\
\hline E. coli $\mathrm{DH} 5 \alpha$ & pCLL3410 & $\begin{array}{l}\text { 9-kb BamHI fragment containing the pI } 7.6 \text { (SHV-7) } \beta \text {-lactamase from MCQ-2 } \\
\text { in pCLL2300 }\end{array}$ & This study \\
\hline E. coli $\mathrm{DH} 5 \alpha$ & pCLL3411 & 6.5-kb $B g l I I$ fragment containing SHV-1 $\beta$-lactamase from SC10999 in pCLL2300 & This study \\
\hline
\end{tabular}

studies were performed by incubating the inhibitor with purified enzyme for 10 min prior to the addition of nitrocefin at $50 \mu \mathrm{g} / \mathrm{ml} \mathrm{(27).} \mathrm{The} \mathrm{concentration}$ required for inhibition of $50 \%$ of the enzyme activity was determined graphically.

Nucleic acid techniques. Plasmids conferring ceftazidime resistance were transferred from the clinical isolates to a susceptible $E$. coli host by filter mating, selecting for ceftazidime and chloramphenicol resistance. Plasmid DNA was isolated by alkaline lysis from the clinical isolates and the resulting transconjugants (6). Restriction enzyme digestions, recombinant DNA techniques, and transformations of plasmid DNA were performed as described by Sambrook et al. (30). Pulsed-field gel electrophoresis (PFGE) was performed as described by Maslow et al. (15) with a CHEF Mapper apparatus (Bio-Rad Laboratories, Hercules, Calif.). DNA insert blocks were digested overnight with $\mathrm{XbaI}$

To facilitate nucleotide sequencing, a 9-kb BamHI fragment encoding the $\beta$-lactamase with a pI of 7.6 from strain MCQ-3 was cloned into pCLL2300, a kanamycin resistance-conferring cloning vector (28), and the resulting plasmid was designated pCLL3410. Both strands of the entire SHV gene were sequenced with a nested set of primers identical and complementary to the SHV-1-coding sequence. These were selected so that they did not anneal to regions of the gene corresponding to base pair changes associated with previously determined extended-spectrum SHV gene DNA sequences. DNA sequencing was performed on double-stranded plasmid DNA with a Sequenase kit (United States Biochemical, Cleveland, Ohio) with $\left[{ }^{35}\right.$ S]dATP label (Amersham, Arlington Heights, Ill.) according to the manufacturer's instructions.

Southern blot analyses were performed on plasmid DNA with the Rad-Free kit (Schleicher \& Schuell, Keene, N.H.), which uses a psoralen biotin label for probe nucleic acids, according to the manufacturer's instructions. An 850-bp NdeI-EcoRI fragment, which contained most of the coding region for the TEM-1 $\beta$-lactamase gene from pUC19, was isolated from pCLL2306 (Table 1) and was used as the probe for TEM $\beta$-lactamase genes. A 467-bp NotI-PstI fragment containing an internal region of the SHV-1 gene was isolated from pCLL3411 (Table 1) and was used as the probe for SHV $\beta$-lactamase genes.

Nucleotide sequence accession number. The nucleotide sequence data reported here will appear in the GenBank nucleotide sequence database under accession no. U20270.

\section{RESULTS}

Epidemiology. Four clinical isolates of E. coli (strains MCQ-1 to MCQ-4), which were resistant to extended-spectrum $\beta$-lactam antibiotics, were cultured from the urine of elderly patients (strains corresponding to patients 1 to 4 , respectively) at NYHMCQ between May and December 1993. These four strains were the first ceftazidime-resistant $E$. coli isolates to appear at NYHMCQ in conjunction with a continuous low-level resistance to ceftazidime in $K$. pneumoniae. Three of the patients from whom the ceftazidime-resistant $E$. coli strains were isolated (patients 1, 3, and 4) were admitted from area nursing homes and had positive urine cultures upon admission. None of the three patients was from the same nursing home. Patient 2 was admitted from home and acquired the resistant $E$. coli strain in the hospital. There was an overlap in the admission periods for patients 3 and 4 but not for patient 1 or 2 . None of the four patients was receiving antibiotic therapy at the time of admission; however, patient 3 had received numerous antibiotics in the past, including ampicillin, gentamicin, ciprofloxacin, cefuroxime, cefazolin, and cephalexin.

As shown in Fig. 1A, plasmid analysis of strains MCQ-2, MCQ-3, and MCQ-4 by agarose gel electrophoresis revealed that these three strains had identical patterns. Each strain possessed at least seven plasmid bands ranging in size from approximately $<1$ to $>40 \mathrm{~kb}$. To determine the strain relatedness of the clinical isolates, chromosomal DNAs prepared from strains MCQ-1, MCQ-2, MCQ-3, and MCQ-4 were examined by PFGE. The results showed that strains MCQ-2,
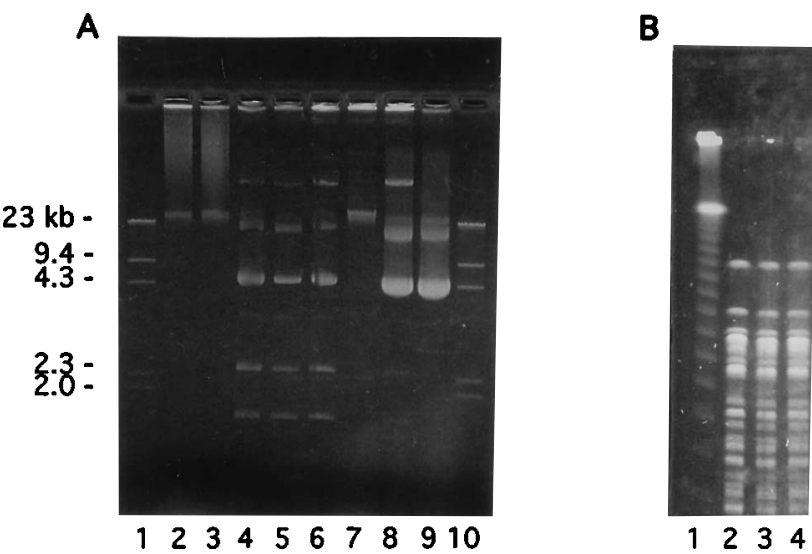

FIG. 1. Molecular epidemiology of clinical isolates. (A) Plasmid profiles of clinical isolates, transconjugants, and transformants. Lanes 1 and 10 , bacteriophage $\lambda$ HindIII molecular size marker; lane 2, MCQ-1; lane 3, MCQ-1X; lane 4, MCQ-2; lane 5, MCQ-3; lane 6, MCQ-4; lane 7, MCQ-3Xa; lane 8, MCQ-3Xb; lane 9, MCQ-3T. (B) PFGE of clinical isolates. Lane 1, bacteriophage $\lambda$ ladder; lane 2, MCQ-2; lane 3, MCQ-3; lane 4, MCQ-4. 
TABLE 2. MICs of various $\beta$-lactam drugs for E. coli clinical isolates and strains from the study

\begin{tabular}{|c|c|c|c|c|c|c|c|c|c|c|c|}
\hline \multirow{2}{*}{ E. coli strain } & \multirow{2}{*}{$\begin{array}{c}\mathrm{pI} \text { of } \\
\beta \text {-lactamase }\end{array}$} & \multicolumn{10}{|c|}{$\operatorname{MIC}(\mu \mathrm{g} / \mathrm{ml})^{a}$} \\
\hline & & SAM & TIM & P-T $(+4)$ & P-T (8:1) & $\mathrm{CAZ}$ & CTX & ATM & FOX & CTT & IPM \\
\hline MCQ-1 & 5.6 & 8 & 4 & 1 & 4 & $>128$ & $\leq 1$ & 32 & 4 & 1 & $\leq 2$ \\
\hline MCQ-2 & $5.4,7.6$ & 32 & 128 & 32 & 16 & $>128$ & $>128$ & $>64$ & 8 & 2 & $\leq 2$ \\
\hline MCQ-3 & $5.4,7.6$ & 64 & $>128$ & 64 & 32 & $>128$ & 128 & 64 & 8 & 2 & $\leq 2$ \\
\hline MCQ-4 & $5.4,7.6$ & 64 & $>128$ & 32 & 32 & $>128$ & $>128$ & $>64$ & 8 & 1 & $\leq 2$ \\
\hline CAG12027 & & 4 & 4 & 1 & 1 & $\leq 0.5$ & $\leq 0.5$ & $\leq 0.5$ & 2 & $\leq 0.5$ & $\leq 0.5$ \\
\hline MCQ-3Xa & 5.4 & 32 & 64 & 2 & 4 & $\leq 0.5$ & 1 & $\leq 2$ & 8 & $\leq 2$ & $\leq 0.5$ \\
\hline MCQ-3Xb & $5.4,7.6$ & 128 & $>128$ & 64 & 32 & $>128$ & $>128$ & $>128$ & 38 & $\leq 2$ & $\leq 0.5$ \\
\hline $\mathrm{DH} 5 \alpha$ & & 2 & 4 & 0.5 & 0.5 & $\leq 0.5$ & $\leq 0.5$ & $\leq 0.5$ & 4 & $\leq 0.5$ & $\leq 0.5$ \\
\hline MCQ-3T & $5.4,7.6$ & 64 & $>128$ & $>128$ & 64 & $>128$ & $>128$ & $>128$ & 8 & $\leq 2$ & $\leq 0.5$ \\
\hline DH5 $\alpha($ pCLL2300) & & 2 & 4 & 0.5 & 0.5 & $\leq 0.5$ & $\leq 0.5$ & $\leq 0.5$ & 2 & $\leq 0.5$ & $\leq 0.5$ \\
\hline DH $5 \alpha(\mathrm{pCLL} 3410)$ & 7.6 & 8 & 32 & 1 & 8 & $>128$ & 32 & $>128$ & 2 & $\leq 2$ & $\leq 0.5$ \\
\hline
\end{tabular}

${ }^{a}$ MICs were determined in broth macrodilution tests (19). SAM, ampicillin-sulbactam; TIM, ticarcillin-clavulanate; P-T, piperacillin-tazobactam (+4, constant concentration of $4 \mu \mathrm{g}$ of tazobactam per ml; 8:1, fixed 8:1 ratio of piperacillin to tazobactam); CAZ, ceftazidime; CTX, cefotaxime; ATM, aztreonam; FOX, cefoxitin; CTT, cefotetan; IPM, imipenem.

MCQ-3, and MCQ-4 were completely identical (Fig. 1B), whereas strain MCQ-1 was unique.

Susceptibility. The MICs of selected $\beta$-lactam antibiotics for the clinical isolates, transconjugants, transformants, and clones are given in Table 2. All four of the clinical isolates were resistant to ceftazidime and aztreonam. Strains MCQ-2, MCQ-3, and MCQ-4 also had increased levels of resistance to ampicillin-sulbactam, ticarcillin-clavulanate, piperacillin-tazobactam, and cefotaxime. All of the clinical isolates remained susceptible to cefoxitin, cefotetan, and imipenem. In addition, all four clinical isolates were resistant to streptomycin, gentamicin, kanamycin, and sulfisoxazole. Strains MCQ-2, MCQ-3, and MCQ-4 were also resistant to naladixic acid, ciprofloxacin, and trimethoprim-sulfamethoxazole.

$\boldsymbol{\beta}$-Lactamase characterization. The pIs of the $\beta$-lactamases present in crude extracts obtained from the clinical isolates are given in Table 2. Clinical isolates MCQ-2, MCQ-3, and MCQ-4 each expressed two $\beta$-lactamases, one with a pI of 5.4, which correlates with the TEM-1 $\beta$-lactamase, and one with a pI of 7.6, which is compatible with an SHV-type $\beta$-lactamase. The pI $5.4 \beta$-lactamase did not confer resistance to any of the extended-spectrum $\beta$-lactams tested. However, the presence of the $\mathrm{pI}$ 7.6 $\beta$-lactamase correlated with resistance to cefotaxime as well as with resistance to ceftazidime and aztreonam (Table 2). Strain MCQ-1 produced a single $\beta$-lactamase with a $\mathrm{pI}$ of 5.6 and was later determined to be TEM-10 (data not shown).

Initial $\beta$-lactamase assays with the pI 5.4 enzyme purified from MCQ-3 revealed that hydrolysis of ceftazidime, cefotaxime, and aztreonam was less than $1 \%$ that of benzylpenicillin (data not shown). Inhibition studies showed that this enzyme was inhibited well by clavulanic acid and tazobactam

TABLE 3. Inhibition of purified $\beta$-lactamases by commercially available $\beta$-lactamase inhibitors

\begin{tabular}{lcccc}
\hline \multirow{2}{*}{$\begin{array}{c}\text { Strain or } \\
\text { plasmid }\end{array}$} & $\beta$-Lactamase & \multicolumn{3}{c}{$\mathrm{IC}_{50}(\mathrm{nM})^{a}$} \\
\cline { 3 - 5 } & & Clavulanic acid & Sulbactam & Tazobactam \\
\hline SC 10404 & TEM-1 & 15 & 560 & 6.6 \\
MCQ-3 & TEM-1 & 16 & 1,500 & 34 \\
pCLL3411 & SHV-1 & 6.4 & 2,900 & 110 \\
pBP60 & SHV-2 & 1.8 & 560 & 50 \\
pUD21 & SHV-4 & 3.3 & 550 & 24 \\
MCQ-3 & SHV-7 & 4.4 & 350 & 42 \\
\hline
\end{tabular}

${ }^{a} \mathrm{IC}_{50}, 50 \%$ inhibitory concentration.
(Table 3). Therefore, this enzyme was determined to have properties consistent with that of the TEM-1 $\beta$-lactamase.

In IEF experiments, crude extracts prepared from strains expressing the SHV-7 $\beta$-lactamase showed a band which aligned with SHV-1 at a $\mathrm{pI}$ of 7.6. However, the enzyme purified from DH5 $\alpha$ (pCLL3410) focused with a slightly higher pI. The same phenomenon was seen in our laboratory with the crude and purified preparations of SHV-4. Therefore, the substrate profile of the purified novel SHV-7 $\beta$-lactamase (pI 7.6 $\beta$-lactamase from MCQ-3) is given in Table 4 and compared with the profiles determined for both SHV-2 and SHV-4, which have reported pIs of 7.6 and 7.8 , respectively $(8,14)$. This enzyme has characteristics which are quite different from those of either reference enzyme in that it hydrolyzed ceftazidime at a faster rate than SHV-2 or SHV-4 did. In addition, the $K_{m}$ value of SHV-7 for aztreonam was 71- and 25-fold lower than those of SHV-2 and SHV-4, respectively.

Plasmid characterization. Clinical strains MCQ-2, MCQ-3, and MCQ-4 were mated to a susceptible E. coli strain (CAG12027), and transconjugants were selected on ampicillin and chloramphenicol. Transconjugants that expressed the TEM-1 $\beta$-lactamase either alone or in combination with the $\mathrm{pI}$ $7.6 \beta$-lactamase could be selected. When the mating experiment was repeated with selection on cefotaxime and chloramphenicol, all of the resulting transconjugants expressed both the TEM-1 $\beta$-lactamase and the pI $7.6 \beta$-lactamase. The transconjugants expressing the TEM-1 $\beta$-lactamase possessed two plasmids, with their molecular sizes estimated to be approximately 40 and $25 \mathrm{~kb}$, whereas the transconjugants that expressed two $\beta$-lactamases (TEM-1 and pI 7.6) possessed three plasmids with molecular sizes of approximately 40, 25, and $10 \mathrm{~kb}$ (Fig. 1A).

When plasmid DNAs from clinical strains MCQ-2, MCQ-3, and MCQ-4 were transformed into $E$. coli $\mathrm{DH} 5 \alpha$ the resulting transformants all possessed two plasmids with molecular sizes of approximately 25 and $10 \mathrm{~kb}$. The transformants also expressed both the TEM-1 $\beta$-lactamase as well as the pI 7.6 $\beta$-lactamase.

To determine on which plasmid the gene encoding the pI 7.6 $\beta$-lactamase resided and whether the pI $7.6 \beta$-lactamase was actually an SHV-type enzyme, a Southern blot was performed on clinical isolates MCQ-2, MCQ-3, and MCQ-4, their transconjugants, and their transformants by using internal probes for both TEM-1 and SHV-1 genes. The results showed that the TEM-1 probe hybridized with the $25-\mathrm{kb}$ plasmid, while 
TABLE 4. Substrate profiles of purified SHV $\beta$-lactamases

\begin{tabular}{|c|c|c|c|c|c|c|}
\hline \multirow[b]{2}{*}{ Substrate } & \multicolumn{2}{|c|}{ MCQ-3, SHV-7 } & \multicolumn{2}{|c|}{ pBP60, SHV-2 } & \multicolumn{2}{|c|}{ pUD21, SHV-4 } \\
\hline & $\begin{array}{c}K_{m} \\
(\mu \mathrm{M})\end{array}$ & $\begin{array}{c}\text { Relative } \\
V_{\max }\end{array}$ & $\begin{array}{c}K_{m} \\
(\mu \mathrm{M})\end{array}$ & $\begin{array}{c}\text { Relative } \\
V_{\max }\end{array}$ & $\begin{array}{c}K_{m} \\
(\mu \mathrm{M})\end{array}$ & $\begin{array}{c}\text { Relative } \\
V_{\max }\end{array}$ \\
\hline Benzylpenicillin & 6.5 & 100 & 3.8 & 100 & 12 & 100 \\
\hline Cephaloridine $^{a}$ & 13 & 91 & 20 & 130 & 10 & 5.6 \\
\hline Ceftazidime & 24 & 13 & 41 & 0.51 & 17 & 0.65 \\
\hline Cefotaxime & 11 & 30 & 7.8 & 19 & 4.6 & 1.1 \\
\hline Aztreonam & 13 & 3.3 & 920 & 1.5 & 330 & 0.056 \\
\hline Cephalothin & 2.7 & 35 & & $\mathrm{ND}^{b}$ & & ND \\
\hline Carbenicillin & 3.9 & 15 & & ND & & ND \\
\hline Cloxacillin & 33 & 27 & & ND & & ND \\
\hline Cefoxitin & $\mathrm{NC}^{c}$ & $<1$ & & ND & & ND \\
\hline Cefotetan & $\mathrm{NC}$ & $<1$ & & ND & & ND \\
\hline Imipenem & $\mathrm{NC}$ & $<1$ & & ND & & ND \\
\hline
\end{tabular}

${ }^{a}$ For SHV-7, SHV-2, and SHV-4, the specific activities of cephaloridine were 160,92 , and $57 \mathrm{nmol}$ of substrate hydrolyzed/min $/ \mathrm{mg}$ of protein, respectively.

${ }^{b} \mathrm{ND}$, not determined.

${ }^{c} \mathrm{NC}$, not calculated (rate was too slow to obtain reliable values).

the SHV-1 probe hybridized with the $10-\mathrm{kb}$ plasmid (data not shown).

Nucleotide sequencing. The pI 7.6 SHV-type $\beta$-lactamase gene from MCQ-3 was cloned (pCLL3410), and nucleotide sequencing was performed. Because the plasmids encoding the pI 7.6 $\beta$-lactamase in strains MCQ-2, MCQ-3, and MCQ-4 hybridized with an SHV-1 probe, the gene was sequenced with a set of oligonucleotide primers which were complementary to both strands of the SHV-1 gene. The only nucleotide sequence which has been published for SHV-1 contains a number of residues that are not found in the nucleotide or amino acid sequences of any of the other SHV-type $\beta$-lactamases (17). For this reason, the entire nucleotide sequence and predicted amino acid sequence for SHV-7 are shown in Fig. 2.

Although there is sequence homology for the gene encoding SHV-7 and the sequences given for other SHV-type genes (10, $17,22,25,31)$ in the noncoding region upstream through the -35 consensus sequence, there appears to be less homology in regions farther upstream or regions downstream from the termination codon. The amino acid sequence predicted from the nucleotide sequence showed four amino acid substitutions compared with the amino acid sequence of the SHV-1 protein; phenylalanine for isoleucine at position 8 , serine for arginine at position 43, serine for glycine at position 238, and lysine for glutamate at position 240 . The substitution of a serine at position 238 is shared by the genes encoding SHV-2, SHV-3, SHV-4, and SHV-5 (Table 5) and appears to be implicated in the extended spectra of these $\beta$-lactamases. The substitution of a lysine at position 240 , adjacent to position 238 , is also shared by genes encoding the SHV-4 and SHV-5 $\beta$-lactamases. The substitutions of a phenylalanine at position 8 , in the leader sequence of the protein, and the serine at position 43 , in the mature protein, are identical to those in the OHIO-1 $\beta$-lactamase but are not found in other SHV enzymes (Table 5). Because of these four unique amino acid substitutions, the pI 7.6 enzyme from MCQ-3 appears to be a novel extendedspectrum $\beta$-lactamase and has been designated SHV-7.

Nucleotide sequence accession number. The nucleotide sequence data reported here will appear in the GenBank nucleotide sequence data base under accession number U20270.

\section{DISCUSSION}

Noteworthy in this study is the characterization of a novel extended-spectrum SHV-type $\beta$-lactamase, designated here as
SHV-7. Molecular epidemiology determined by using plasmid profiles and PFGE showed that the three strains which expressed the SHV-7 $\beta$-lactamase were identical. Whereas one of the isolates followed a nosocomial infection, the other two infecting organisms were from two patients who were admitted to NYHMCQ from separate nursing homes. This indicates that the patients had been colonized with the resistant organisms and most likely developed the infections from their own normal flora. Therefore, this strain appears to have been disseminated throughout the populations of the nursing homes prior to the time of strain isolation and that the nursing homes now serve as a reservoir for ceftazidime- and cefotaxime-resistant strains. The emergence of this enzyme in this patient population provides added protection to the organisms in that it confers resistance to cefotaxime in addition to ceftazidime and aztreonam. It is also interesting that the enzyme was found in combination with a TEM-1 enzyme produced at high levels, which also made the strain resistant to the $\beta$-lactam-inhibitor combinations.

The amino acid sequence predicted from the nucleotide sequence of the gene encoding the SHV-7 $\beta$-lactamase is unique from those of other SHV-type genes $(4,5,10,17,22$, $23,25,31)$. Although a sequence has not been published for the gene encoding SHV-6, which also has a pI of 7.6, the SHV-6 enzyme specifically confers resistance to ceftazidime but not to cefotaxime or aztreonam (3). Therefore, it is unlikely that the SHV-6 $\beta$-lactamase and the SHV-7 $\beta$-lactamase reported here are the same. The SHV-2, SHV-3, SHV-4, SHV-5, and SHV-7 $\beta$-lactamase genes all possess a serine-forglycine substitution at position $238(4,5,22,23)$ which is believed to be responsible for the hydrolysis of cefotaxime by these extended-spectrum SHV-type $\beta$-lactamases $(4,12)$. The substitution of a lysine for a glutamate at position 240 seen in SHV-4, SHV-5, and SHV-7 is also thought to contribute to the expanded spectra of these enzymes to include ceftazidime and aztreonam $(12,23)$. The substitutions at consecutive positions 238 and 240 follow closely after the conserved Box VII at positions 234 to 236 described by Joris et al. (13), which is responsible for cephalosporinase activity. Likewise, the substitution of serine for arginine at position 43 is very near the beginning of conserved Box I (residues 46 to 50), although the significance of this is not clear. One of the sequences which has been published for SHV-2 contains an amino acid substitution of tryptophan for leucine at position 20 in the leader peptide region (24). Like the substitution seen in the leader peptide of SHV-7, a similar amino acid was substituted. The roles of residues 8 and 20 in the localization of the $\beta$-lactamase protein are unclear.

The substitutions of phenylalanine for alanine at position 8 and serine for arginine at position 43 found in the SHV-7 $\beta$-lactamase are shared with the OHIO-1 $\beta$-lactamase but not other SHV-type enzymes (31). This does not necessarily suggest an evolutionary link between the two genes because the OHIO-1 gene differs from the SHV-1 gene at 11 other residues and the SHV-7 gene at 13 residues. It would, however, suggest that there is a reason for the selection of specific amino acid substitutions at positions 8 and 43 .

There is little homology of the nucleotide sequences upstream and downstream from the structural $b l a_{\mathrm{SHV}}$ genes. Thus, it is unlikely that these genes reside on a common transposon (24). There has also been some degree of variation of the DNA sequences reported for the structural genes. The only nucleotide sequence which has been published for the SHV-1 $\beta$-lactamase gene, by Mercier and Levesque (17), contains a number of substitutions which result in six amino acids that are not found in any of the other $b l a_{\mathrm{SHV}}$ genes. These substitutions 


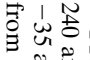

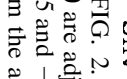

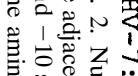

傗

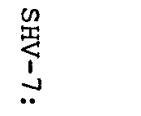

$\sum_{\substack{1 \\:}}^{n}$

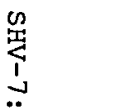

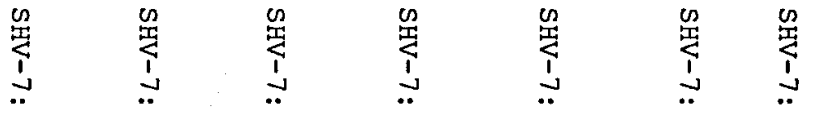

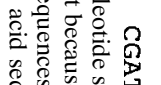

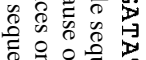

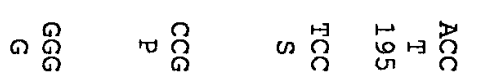

• ำ

十学点

<曷

的觉

四密》

ㅇำ

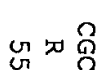

๒ กิก

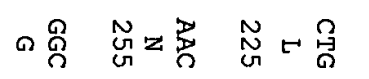

$1 ?$

เ⿳⺈⿴囗十大

↔

我路

<曷

$\mapsto$ 常

1

象. 差

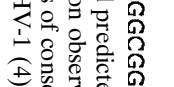

$>$ 员 짐

㖞㟔口嘗

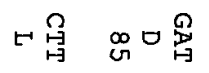

量

v 尺ิ

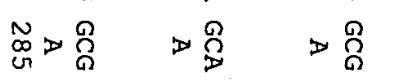

동

<曷

$x \stackrel{\circ}{ก}$

เ ถู

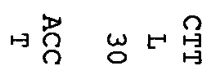

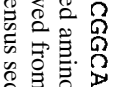

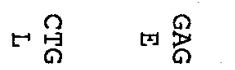

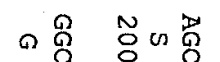

四亮

ه合岕口带

ค 命

$\rightarrow \frac{\text { ว }}{2}$

凶

$>\stackrel{\Omega}{0}$

ธ คิ คิ

ด命

哫

学吹 合

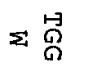

$>$ مิ

๘哥点四

学

由

๓ กิ

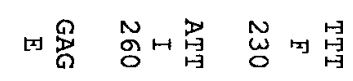

刃 คิด

๙

$\rightarrow$

$\mapsto$ 学

$80 ?$

$\infty$ กิ

口密

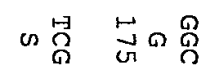

○量<甾

$\rightarrow ?$

$\square$

H盆

谘 <曷

H昌

$10 ?$

吩

七曷 岕口员

凶煦

खा

$\pi$

ง滘

w口畕

吗的急

喝

萬雨

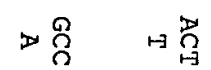

ए马

* क्रि

吹命曷

为

10

๓

芹》

* 㟧世界岕

동

○

为曷

동

$x$

时曷

喝品㫷吹

火

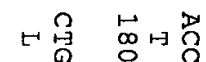

녑

$\rightarrow \stackrel{\circ}{\Omega}$

또

学

谞量

10

$\mapsto$

0

心

く曷

学

ค岇

๒ ถั

苔 $\Sigma$ 员

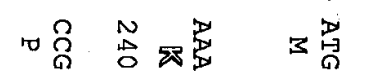

ต

10 葛

$\rightarrow \frac{\Omega}{n}$

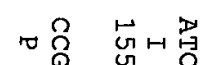

$\underset{0}{\sim} \rightarrow 0$

ำ ดิ

$<$ 昌

$\rightarrow \stackrel{\circ}{ก}$

ค คे

的 $\triangle$ 员

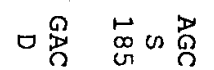

○星

学

ग

和究

○雚

$\rightarrow \stackrel{8}{8}$

⿰ง ⿵人丶

了学 命

蛋

3

$>\stackrel{\Omega}{\Omega}$

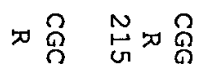

$\rightarrow$ กิ

$z$ 宸

3

ㅇํㅇ윰

四莬念口曷

<的

$>\frac{\pi}{\circ}$

《煦

幽的

口蛋

小

ख

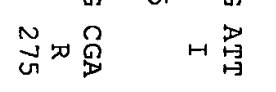

홍ํํㅇ

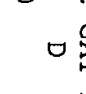

只

幽密

क क ด

10 莡

낭봉

으용

○吕

$H$

๘

十学

๘ ํํํ

๑ คิ

营《曷

$>$ مิ

↔

๓ล ด

25

$<$

<号

<曷

只早

○号

옹

○寈吕场

돕

कs

둥송

口穴

cอ 突

它此昌

$<9$

品口令

5

$>$

贻 命

๙ คิ

๓ กิ

$\square$

क 㖞

a ด

3 煦

象

5

Nㄴ봉

$x$

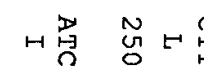

十窎

동

ข

$\underset{w}{\omega} \gg \hat{n}$

ซ ถุ

$>\stackrel{\circ}{\circ}$

$H$

冓员

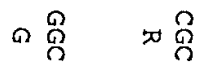

ำ

돋ํㅇ

蛋

<品 为<昌

哟

เ

เ

$N$ ㅇ

蒿

㥈

四密

동

的窝㖞

3昌

เ苗

ज 0 总

$>$

동 
TABLE 5. Comparative amino acid sequences of SHV-type $\beta$-lactamases at selected positions

\begin{tabular}{lccccccl}
\hline \multirow{2}{*}{$\beta$-Lactamase } & \multirow{2}{*}{$\begin{array}{c}\mathrm{pI} \text { of } \\
\beta \text {-lactamase }\end{array}$} & \multicolumn{5}{c}{ Amino acid at position ${ }^{a}:$} & \multirow{2}{*}{ Reference } \\
\cline { 3 - 6 } & & 8 & 43 & 205 & 238 & 240 & \\
\hline SHV-1 & 7.6 & Ile & Arg & Arg & Gly & Glu & 4,17 \\
SHV-2 & 7.6 & Ile & Arg & Arg & Ser & Glu & $4,10,11$, \\
& & & & & & & 24,25 \\
SHV-3 & 7.0 & Ile & Arg & Leu & Ser & Glu & 22 \\
SHV-4 & 7.8 & Ile & Arg & Leu & Ser & Lys & 23 \\
SHV-5 & 8.2 & Ile & Arg & Arg & Ser & Lys & 5 \\
SHV-7 & 7.6 & Phe & Ser & Arg & Ser & Lys & This study \\
OHIO-1 & 7.0 & Phe & Ser & Arg & Gly & Glu & 31 \\
LEN-1 & 7.0 & Val & Arg & Gln & Gly & Glu & 2,17 \\
\hline
\end{tabular}

${ }^{a}$ Amino acid sequence numbers are according to Ambler et al. (1). Amino acids in boldface type represent changes from SHV-1 (4).

${ }^{b}$ SHV-6 has been described biochemically, but no sequence data are yet available (3).

have not been supported by amino acid sequence data for the SHV-1 $\beta$-lactamase protein (4). However, the amino acid sequences of SHV-1 and SHV-2 reported by Barthélémy et al. (4) showed an inversion of the alanine and threonine at positions 140 and 141 . This reversal has not been reported by other investigators. In addition, the nucleotide sequence for SHV-2 reported by Garbarg-Chenon et al. (10) contained nucleotides which resulted in the substitution of a glutamine for lysine at position 35. It is possible that each of these sequences represents a unique protein that eventually should be designated an SHV-2 variant.

The continued emergence of extended-spectrum $\beta$-lactamases is a concern to all in the health care industry. The fact that there are now at least three different extended-spectrum $\beta$-lactamases, TEM-10, TEM-26, and SHV-7, in a single North American hospital is noteworthy. It is particularly worrisome that the organisms harboring these enzymes have found their way into the normal flora of nursing home patients, especially because the resistance genes have moved into $E$. coli, a very common and previously highly susceptible organism. This phenomenon most likely reflects the overuse of antimicrobial agents in the nursing home setting. A more prudent use of antibiotics in elderly nursing home patients is necessary to reduce the spread of these resistant strains.

\section{ACKNOWLEDGMENTS}

We acknowledge the excellent technical assistance of E. Calcagni for PFGE experiments and M. Spengler for susceptibility tests. We also thank B. Wiedemann and A. A. Medeiros for the kind gifts of strains expressing the SHV-2 and SHV-4 $\beta$-lactamases.

C. Urban, A. Jaiswal, N. Mariano, and J. Rahal were supported by BMA Medical Foundation, Inc.

\section{REFERENCES}

1. Ambler, R. P., A. F. W. Coulson, J.-M. Frére, J.-M. Ghuysen, B. Joris, M. Forsman, R. C. Levesque, G. Tiraby, and S. G. Waley. 1991. A standard numbering scheme for the class A $\beta$-lactamases. Biochem. J. 276:269270

2. Arakawa, Y., M. Ohta, N. Kido, Y. Fujii, T. Komatsu, and N. Kato. 1986. Close evolutionary relationship between the chromosomally encoded $\beta$-lactamase gene of Klebsiella pneumoniae and the TEM $\beta$-lactamase gene mediated by R plasmids. FEBS Lett. 207:69-74.

3. Arlet, G., M. Rouveau, D. Bengoufa, M. H. Nicolas, and A. Philippon. 1991. Novel transferable extended-spectrum $\beta$-lactamase (SHV-6) from Klebsiella pneumoniae conferring selective resistance to ceftazidime. FEMS Microbiol. Lett. 81:57-62.

4. Barthélémy, M., J. Péduzzi, H. B. Yaghlane, and R. Labia. 1988. Single amino acid substitution between SHV-1 $\beta$-lactamase and cefotaxime-hydrolyzing SHV-2 enzyme. FEBS Lett. 231:217-220.
5. Billot-Klein, D., L. Gutmann, and E. Collatz. 1990. Nucleotide sequence of the SHV-5 $\beta$-lactamase gene of a Klebsiella pneumoniae plasmid. Antimicrob. Agents Chemother. 34:2439-2441.

6. Birnboim, H. C., and J. Doly. 1979. A rapid alkaline extraction procedure for screening recombinant plasmid DNA. Nucleic Acids Res. 7:1513-1523.

7. Bradford, P. A., C. E. Cherubin, V. Idemyor, B. A. Rasmussen, and K. Bush 1994. Multiply resistant Klebsiella pneumoniae strains from two Chicago hospitals: identification of the extended-spectrum TEM-12 and TEM-10 ceftazidime-hydrolyzing $\beta$-lactamases in a single isolate. Antimicrob. Agents Chemother. 38:761-766.

8. Buré, A., P. Legrand, G. Arlet, V. Jarlier, G. Paul, and A. Philippon. 1988 Dissemination in five French hospitals of Klebsiella pneumoniae serotype K25 harbouring a new transferable enzymatic resistance to third generation cephalosporins and aztreonam. Eur. J. Clin. Microbiol. Infect. Dis. 7:780782 .

9. Bush, K., and S. B. Singer. 1989. Effective cooling allows sonication to be used for liberation of $\beta$-lactamases from gram-negative bacteria. J. Antimicrob. Chemother. 24:82-84.

10. Garbarg-Chenon, A., V. Godard, R. Labia, and J.-C. Nicolas. 1990. Nucleotide sequence of SHV-2 $\beta$-lactamase gene. Antimicrob. Agents Chemother. 34:1444-1446.

11. Huletsky, A., F. Couture, and R. C. Levesque. 1990. Nucleotide sequence and phylogeny of SHV-2 $\beta$-lactamase. Antimicrob. Agents Chemother. 34:17251732.

12. Huletsky, A., J. R. Knox, and R. C. Levesque. 1993. Role of Ser-238 and Lys-240 in the hydrolysis of 3rd-generation cephalosporins by SHV-type beta-lactamases probed by site-directed mutagenesis and 3-dimensional modeling. J. Biol. Chem. 268:3690-3697.

13. Joris, B., J.-M. Ghuysen, G. Dive, A. Renard, O. Dideberg, P. Charlier, J.-M. Frére, K. A. Kelly, J. C. Boyington, P. C. Moews, and J. R. Knox. 1988. The active-site-serine penicillin-recognizing enzymes as members of the Streptomyces R61 DD-peptidase family. Biochem. J. 250:313.

14. Kliebe, C., B. A. Nies, J. F. Meyer, R. M. Tolxdorff-Neutzling, and B. Wiedemann. 1985. Evolution of plasmid-coded resistance to broad spectrum cephalosporins. Antimicrob. Agents Chemother. 28:302-307.

15. Maslow, J. N., A. M. Slutsky, and R. D. Arbeit. 1993. Application of pulsedfield gel electrophoresis to molecular epidemiology, p. 563-572. In D. H. Persing, T. F. Smith, F. C. Tenover, and T. J. White (ed.), Diagnostic molecular microbiology principles and applications. American Society for Microbiology, Washington, D.C

16. Matthew, M. A., A. M. Harris, M. J. Marshall, and G. W. Ross. 1975. The use of isoelectric focusing for detection and identification of beta-lactamases. J. Gen. Microbiol. 88:169-178.

17. Mercier, J., and R. C. Levesque. 1990. Cloning of SHV-2, OHIO-1, and OXA-6 $\beta$-lactamases and cloning and sequencing of SHV-1 $\beta$-lactamase. Antimicrob. Agents Chemother. 34:1577-1583.

18. Meyer, K. S., C. Urban, J. A. Eagan, B. J. Berger, and J. J. Rahal. 1993. Nosocomial outbreak of Klebsiella infection resistant to late generation cephalosporins. Annu. Intern. Med. 119:353-358.

19. National Committee for Clinical Laboratory Standards. 1994. Methods for dilution antimicrobial susceptibility tests for bacteria that grow aerobically. Approved standard M7-A2. National Committe for Clinical Laboratory Standards, Villanova, $\mathrm{Pa}$

20. National Committee for Clinical Laboratory Standards. 1994. Performance standards for antimicrobial disk susceptibility tests. Approved standard M2A4. National Committee for Clinical Laboratory Standards, Villanova, $\mathrm{Pa}$.

21. Naumovski, L., J. P. Quinn, D. Miyashiro, M. Patel, K. Bush, S. B. Singer, D. Graves, T. Palzkill, and A. M. Arvin. 1992. Outbreak of ceftazidime resistance due to a novel extended-spectrum $\beta$-lactamase in isolates from cancer patients. Antimicrob. Agents Chemother. 36:1991-1996.

22. Nicolas, M.-H., V. Jarlier, N. Honore, A. Philippon, and S. T. Cole. 1989. Molecular characterization of the gene encoding SHV-3 $\beta$-lactamase responsible for transferable cefotaxime resistance in clinical isolates of Klebsiella pneumoniae. Antimicrob. Agents Chemother. 33:2096-2100.

23. Péduzzi, J., M. Barthélémy, K. Tiwari, D. Mattioni, and R. Labia. 1989 Structural features related to hydrolytic activity against ceftazidime of plasmid-mediated SHV-type CAZ-5 $\beta$-lactamase. Antimicrob. Agents Chemother. 33:2160-2163.

24. Podbielski, A., and B. Melzer. 1990. Nucleotide sequence of the gene encoding the SHV-2 $\beta$-lactamase (bla $\mathrm{SHV}_{\mathrm{SH}}$ ) of Klebsiella ozaenae. Nucleic Acids Res. 18:4916.

25. Podbielski, A., J. Schönling, B. Melzer, K. Warnatz, and H.-G. Leusch. 1991 Molecular characterization of a new plasmid-encoded SHV-type $\beta$-lactamase (SHV-2 varient) conferring high-level cefotaxime resistance upon Klebsiella pneumoniae. J. Gen. Microbiol. 137:569-578.

26. Quinn, J. P., D. Miyashiro, D. Sahm, R. Flamm, and K. Bush. 1989. Novel plasmid-mediated $\beta$-lactamase (TEM-10) conferring selective resistance to ceftazidime and aztreonam in clinical isolates of Klebsiella pneumoniae. Antimicrob. Agents Chemother. 33:1451-1456.

27. Rasmussen, B. A., P. A. Bradford, J. P. Quinn, J. Wiener, R. A. Weinstein, and K. Bush. 1993. Genetically diverse ceftazidime resistant isolates from a 
single center: biochemical and genetic characterization of TEM-10 $\beta$-lactamases encoded by different nucleotide sequences. Antimicrob. Agents Chemother. 37:1989-1992.

28. Rasmussen, B. A., Y. Gluzman, and F. P. Tally. 1990. Cloning and sequencing of the class B $\beta$-lactamase gene (ccrA) from Bacteroides fragilis TAL3636. Antimicrob. Agents Chemother. 34:1590-1592.

29. Rice, L. B., S. H. Willey, G. A. Papanicolaou, A. A. Medieros, G. M. Eliopoulos, J. R. C Moellering, and G. A. Jacoby. 1990. Outbreak of ceftazidime resistance caused by extended-spectrum $\beta$-lactamases at a Massachusetts chronic-care facility. Antimicrob. Agents Chemother. 34:2193-2199.

30. Sambrook, J., E. F. Fritsch, and T. Maniatis. 1989. Molecular cloning: a laboratory manual, vol. 1, 2nd ed., Cold Spring Harbor Laboratory Press, Cold Spring Harbor, N.Y.

31. Shlaes, D. M., C. Currie-McCumber, A. Hull, I. Behlau, and M. Kron. 1990. OHIO-1 $\beta$-lactamase is part of the SHV-1 family. Antimicrob. Agents Chemother. 34:1570-1576.

32. Singer, M., T. A. Baker, B. Schnitzler, S. M. Deischel, M. Goel, W. Dove,
K. J. Jaacks, A. D. Grossman, J. W. Erickson, and C. A. Gross. 1989. A collection of strains containing genetically linked alternating antibiotic resistance elements for genetic mapping of Escherichia coli. Microbiol. Rev. 53:1-24.

33. Sykes, R. B., D. P. Bonner, K. Bush, and N. H. Georgopapadakou. 1982. Azthreonam (SQ 26,776), a synthetic monobactam specifically active against aerobic gram-negative bacteria. Antimicrob. Agents Chemother. 21:85-92.

34. Urban, C., K. S. Meyer, N. Mariano, J. J. Rahal, R. Flamm, B. A. Rasmussen, and K. Bush. 1994. Identification of TEM-26 $\beta$-lactamase responsible for a major outbreak of ceftazidime-resistant Klebsiella pneumoniae. Antimicrob. Agents Chemother. 38:392-395.

35. Wiener, J., J. Quinn, C. Nathan, P. A. Bradford, K. Bush, R. Goering, and R. A. Weinstein. 1994. Molecular epidemiology of plasmid-mediated ceftazidime resistance in E. coli and Klebsiella pneumoniae in community nursing homes, abstr. C44. p. 87. In Program and abstracts of the 34th Interscience Conference on Antimicrobial Agents and Chemotherapy. American Society for Microbiology, Washington, D.C. 